\title{
'BIG, HARD and UP!' A healthy creed for men to live by?
}

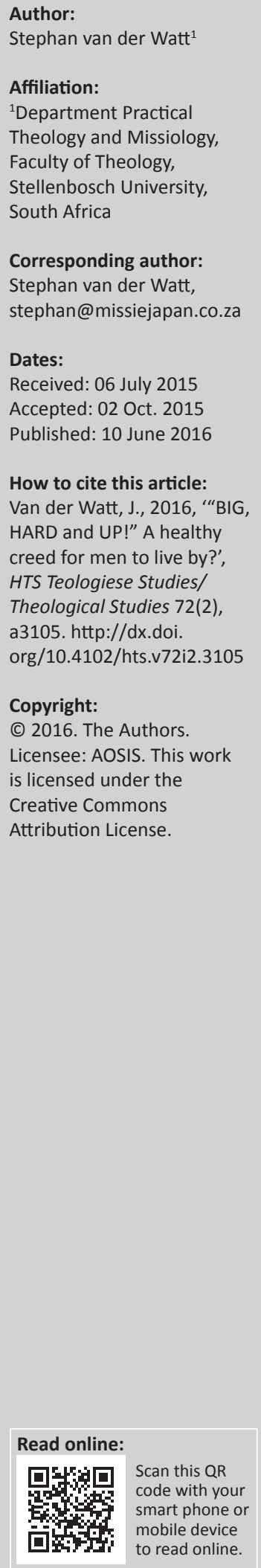

\begin{abstract}
The social construction of reality is influenced extensively by the mass media. Commercialised images of masculinity, including discourses to interpret it, are continuously reflected and/or created by sources of mass media, in a myriad of ways. These images are subjectively loaded, but still effectively communicate to us, and even entice and persuade us. It furthermore wields extensive power over men - especially over their self-images, passions, and egos. In this article, dominating images and discourses concerning manhood and male identity particularly those displayed in men's health magazines (MHM) - were critically examined. This was done through a thematic analysis of 123 issues (spanning more than 10 years) of MHM cover pages. The investigation showed that MHM is infused with traditional masculine ideology. Moreover, MHM fails to confront discourses that endorse hegemonic masculinity, for the sake of holistic health. It was suggested that a sober, precautionary, health strategy should challenge men to critically engage with MHM's reigning creed: 'big, hard and up'. This creed incites a utilitarian view of sexuality within a culture of performance-driven masculinity, which subsequently fuels anxieties that can lead to unhealthy issues, such as body image dissatisfaction. From a pastoral care perspective, it was asserted that (specifically) Christian men need to search for alternative ways to instigate their capacity to experience and facilitate authentic intimacy, in order to work toward the social construction of more balanced and healthy discourses on male identity.
\end{abstract}

\section{Introduction}

The socio-psychological importance of contemporary mass media within a consumerist society cannot be overestimated. Global networks are progressively connected and simultaneously diverse in terms of cultures. It comprises a hypertext with astonishing integrative capacities (Castells 1999; Chamberlain \& Hodgetts 2008). Our different contexts are more and more saturated with diverse media and networks of communication. These networks send intentional messages to targeted parts of audiences. Therefore, within this so-called Network Society ${ }^{1}$ where media networks also reconstruct power relationships, mass media are vitally important in maintaining modern culture. Popular music, advertising, television, and other forms of media culture such as magazines, set forth global icons, lifestyle images, and fashion hints, as well as gendered role models. It was indicated by Durham and Kellner (2001) that:

...discourses and narratives within media cultures offer moral messages, ideological conditioning, and various patterns of proper and improper behaviour, sugar coating social and political ideas with pleasurable and seductive forms of popular entertainment. (p. 1)

Being a Christian today implies cautious but intentional as well as meaningful engagement with current media and culture. Furthermore, pastoral caregivers and practical theologians need to be more aware of the significant power of media images. We need to discover effective ways to scrutinise these images. And we need to find opportunities to influence that which so pervasively (even if subconsciously) shapes us. By theologically exploring magazines, we concretise practical (and pastoral) theology as valid interpretation - in other words hermeneutical analysis - of culture. We then engage in interpreting the material in these forms of media as expressions of core themes in society, in effect re-presenting aspects of globalising culture in theological terms.
1.The Network Society can be defined as a major upcoming social structure system that was started after the 1950's. Castells (1999:398-400)
asserts that it is a typical feature of global (non-industrial) capitalism, based on information technology. Castells highlights the composition
and interrelatedness of this so-called Network Society, which he contends, is the outcome of the merging of three independent processes
in the flow of history, namely in short: (a) the information technology revolution (1970s); (b) the reorganization of capitalism and statism
(1980s); and the cultural social movements with its concomitant effects, specifically feminism and ecologism (1960-1970s).

Note: This article was partially presented as an academic paper at a conference which was held at Stellenbosch University in September 2012, called Work/Force: South African Masculinities in the Media. Furthermore, for a separate article, which can be viewed as an introduction to this article, see Van der Watt and Louw (2012).

This article is published in the section Practical Theology of the Society for Practical Theology in South Africa. 
In this article I propose that we need a pastoral care hermeneutic ${ }^{2}$ that is sensitive to gender issues. Practically, it should challenge women and men to take responsibility for their lives, in order to bring to the fore vital issues of accountability within the church and broader society. Thus, pastoral theological clarifications concerning the content of men's magazines can and should enhance the co-creation of gendered identities. This can encourage men and women to foster fundamentally healthy and meaningful lives that embody human dignity.

The apparent 'crisis of masculinity' as well as the perpetual critique on men's patriarchal rule, cause confusion about male identity within the quest for equality. Therefore, this article distinctively attempts to focus on a useful yet critical evaluation of the impact of particular mass media representations - that is, those displayed in magazines - on diverse enactments of masculinity. According to Boni (2002:476), these magazines present a kind of 'globalisation of the male body, where the global media represent a single model of masculinity, which is hegemonic and globally disciplined'. Research indicates that diverse men's magazines portray an array of masculinity forms. However, aspects of hegemonic masculinity - that is culturally indicative ideals of masculinity within socially structured relationships where some men are deemed inferior - are indeed intertwined throughout (cf. Ricciardelli, Clow \& White 2010).

As gendered beings, men individually deal with disparities between various discourses of masculinity. Recent studies assert that men's magazines in many ways try to present collective resolutions to these conflicts (Toerien \& Durrheim 2001; Viljoen 2008). Therefore, men's lifestyle magazines are deemed as vital media to investigate in order to grasp male identity more comprehensively. More specifically, this article aims to give a pastoral care perspective on male identity discourses and masculine images as depicted in Men's Health Magazines, within the South African context ${ }^{3}$. This is done in order to enhance the aspect of finding meaning, as well as the manifestation of male identity within a framework of integrated, healthy masculinities.

2.Pastoral Care can be defined as a subfield of study and practice within Practical Theology It aims to highlight resources for spiritual care and healing in a broken world, notably by its focus on the human life cycle. A pastoral-theological world, notably by its focus on the human life cycle. A pastoral-theologica hermeneutic (i.e. framework of interpretation) assesses human life, especially its significance and value, not only in terms of absolute competitiveness or success. Rather, it seeks to interpret God and salvation in terms of existentiallife issues, an to express Christian faith practically, in terms of our human quest for dignity, meaning and identity (cf. Louw 2008.42-50, see also Woodward \& Pattison 2000:119). Amongst other skills it aims to develop pastoral caregivers' capacity to listen with empathy, to respond sensitively, to think contextually and psycho-dynamically about pastoral situations. This is done in order to engage in theological-ethical reflection, and to provide moral leadership in an array of cultural contexts. This article is written from this pastoral care perspective, and its main tenets direct the thematic analysis of Men's Health magazines (as will be described later). It will implicitly guide how I eventually interpret the empirical data, as well as inform how I will (briefly) infer meaning from it.

3.In different cultural contexts, discourses on male identity and masculine images will however be interpreted differently. According to Stella Viljoen (2008:317) 'Men's lifestyle magazines in (British and American) contexts presented men with seff lifestyle magazines in (British and American) contexts presented men with selfa various aspons of (new) manh defined the South African mantext, the question of whether South African men would defined the South African context, the question of whether South African men would be ready for the kind of "answers" provided by the more media-savvy developed world remained'. (own italics)

\section{Men and masculinities in the media - New ways of seeing male identity performed}

Susan Bordo (1999:215) contends that our lives are profoundly influenced, even 'ruled' by images. Lemon (1991:126) asserts that media messages transmit 'preferred meanings', which mirror the concerns of society's dominant group(s). Consequently, the media preserve and revive images and discourses, such as binary gender distinctions, which are consistent with the aims of the dominant group(s). The internet, newspapers, advertisements, music lyrics, and magazines all contain gendered images which can sustain or disrupt our ideas about gender. Therefore, the media fulfils a crucial role in continuing and regulating patriarchal ideology along with the traditional male sex role ${ }^{4}$, often with abusive and dangerous side effects (Van der Watt 2012:92-100).

How we relate to our own emotional needs, our intimate partners, and our bodies, are also pertinently influenced by media images. But in complicated ways, these relations will also be altered by our social interactions and experiences. Transforming discourses and descriptions regarding manhood will, thus, demand a deliberate confrontation with illustrations of power and basic realities of power in social spheres of life. Masculinity can be assumed to be a social construct. Given this conception of masculinity, what part do the media perform in defining it? How do men (as well as women) know what behaviours are 'manly'? In what way can (specifically) Christian men discern between healthier and less healthy depictions of manhood that influence their male identity?

\section{Recent representations of commercialised masculinities and men in the media}

During the early 1980s films, television, and adverts began to display fresh images of masculinities. Similar to the objectification of female bodies, men's bodies were now objectified and portrayed erotically, as part of the growing commercialisation and profiteering on men as sex objects. Female bodies were always packaged as visual erotica, but this sexualisation was now transferred onto the male body, for marketing purposes. According to Tasker (1993:242), the inclination of Hollywood action films leans toward the formation of the male body as spectacle, accompanied by the recognition of masculinity as performance. Most movies still displayed singular support for archetypical, hypermasculine, macho images 5 . However, since the 1970s more and more films and television programmes began to confront some of the traditional notions of masculinity. Men were now also being portrayed as capable of being caring and sensitive, 4.Lemon (1991:183) indicates that masculinity depicted in terms of insistent sexual
desire, forms the main ingredients for today's popular advertising, magazines, hard-
and soft-core pornography etc. This aspect of the archetypical male sex role is
significantly perpetuated by the mass media. Lemon explicates that sexual
illustrations of phallus power - as the conclusive symbol of male virility and
domination - grow rapidly in the mass media.

5.See Pettigrew (2007), who provides examples drawn from early 19th century history to show the pervasiveness of hyper-masculinity in American thought. 
giving rise to (among others) the 'New Man' image of the 1990s and so forth.

Moreover, physical looks and possessions were now deemed as tools that transmit meanings. Young and prosperous masculinity, portrayed sensuously, now became the wellspring for a revived consumerism. Beynon (2002:108109) asserts that the fresh, lustrous men's style magazines functioned as the main conveyance for this business enterprise founded on male narcissism. It has indeed prompted the public mind into the area of an ambiguous and unspecified 'new manism'.

Notwithstanding, new 'types' of men are continuously being created by the media. Before the start of 2000, Millennium man was readily spoken of; between 2003 and 2005 two popular and new catchphrase notions - namely Metrosexual and Übersexual - were minted and popularised by Marian Salzman and others. Famous 'icons' such as popular sportsmen, musicians, and actors spurred the trendsetting. More recently, Salzman (2012:94) contends, 'The pampered man $^{6}$ is alive and well and shopping at a beauty counter near you'.

There is apparent global consensus that masculinities have changed markedly in the last two decades of the twentieth century. But, it appears as though there is no longer any lucid agreement concerning what the 'new man' really represents, and this fact amplifies the so-called crisis of masculinity. Is there evidence of real change in masculinity/masculinities, or has it merely grown into something which is now marketed as a 'branded' or 'design-driven' project? Furthermore, how do these new developments, as reflected in the mass media, hinder or create an integrated - that is emotionally, psychologically, bodily, and spiritually - healthy masculine identity?

\section{Interpreting discourses and images from global men's magazines}

International men's magazines - for example, GQ, FHM, Esquire, Loaded, Maxim, Arena, and GQ - currently exhibit barely dressed women on their covers, and on other pages. These magazines are now brazenly teasing with pornographic material in ways that would, according to Viljoen (2005:41, 60), have been inconceivable even in the early 1990s. These magazines' momentous financial success has caused other media areas to follow suit. Soft-core images are all the more common in advertising, as well as on television, in women's magazines, the internet, and newspapers. However, these nude female expressions all seem to point to a significant fracture in the heterosexual male's self-image. Sharkey (2000) contends that - amidst all their excessive flashing of macho postures, and the seemingly ironic display which accompany them - men's magazines are 'desperately trying to mask the poverty of contemporary masculinity’ (Sharkey 2000:173). 6. In her book Looking Good, Lynne Luciano (2001) addresses in chronological fashion
the new cult of male body image in post-war America, and subsequently the many ways in which men became obsessive about the way they looked.
Men's magazines internationally constitute a new moneymaking enterprise and serve as lifestyle handbooks providing fresh ways of positioning men-in-the-mirror ${ }^{7}$. Viljoen (2008:313) indicates how this may also serve to construct 'consumption-driven or "profitable" masculinities', through new markets for the continual restoration of masculinity (via utilisation). Not all men read these magazines, and everyone who does give them a look, will do so selectively. Nevertheless, it remains an important locus for discourses about masculinity, which are portrayed, replicated, and sometimes even exploited on their cover pages. In light of these assertions I will hereafter offer a more detailed investigation of the primary discourses and images depicted specifically in men's health magazines (MHM). The goal is not just to assess what their main contents denote, but also to critically investigate its effect on integrated (i.e. holistic) male health.

\section{Men's Health Magazine - Something essentially healthy or not!?}

MHM is quite similar to women's lifestyle magazines and has a wider ascription than its title proposes. It differs from many other global men's magazines noted above, in the sense that it features scantily clad men (instead of women) on its covers. MHM's core focus is on men's bodily appearance, highlighting weight loss tips, healthy diets, and fitness programs. It hooks up with types of the new man who regard physique and fitness as primary ideals. Therefore, it clearly mirrors the nineteenth century physical culture heritage, as well as its self-improvement ethos.

MHM furthermore proposes a strong focus on psychology, including a significant amount of tips on improving selfesteem and utilising positive thinking in order to succeed. It also features sexuality advice, from erection problems to advanced techniques, purportedly packed to the brim with tons of 'useful stuff'. But to what extent do strong assertions like 'tons of useful stuff' and/or 'the magazine men live by' (on MHM cover pages) hold truth? Is it possible that poor male health is exacerbated by many men's excessive attempt to try and attain the macho images transmitted by MHM? Can popular, commercialised male lifestyles in effect be perilous to health? How is men's health built up or threatened by the central images and discourses and propagated in MHM? I presume it greatly depends on one's view of integrated health.

According to the WHO (World Health Organisation) (n.d.), health can be defined as 'a state of complete physical, social, and mental well-being, and not merely the absence of disease or infirmity'. It is an affirming notion highlighting social and personal resources, including physical capacities. Moreover,

7.Research (Budgeon 2003; Davis 2002; Pope, Phillips \& Olivardia 2000) indicates that not only women often succumb to the cultural trap of trying to live up to unattainable standards of bodily appeal through aesthetics, body alterations, unattainable standards of bodily appeal through aesthetics, body alterations,
fashion etc. Men are indeed also falling for the same allurement, as component of the move towards consumer-oriented societies. 
it is important to note that there are significant disparities between the health options of lower-class men, men with HIV, prisoners, non-white men, and their relatively privileged white, professional (middle- and upper-class) male equals. Thus, present disputes on the question of men's health should focus enough on personal and particular viewpoints and discourse of maleness.

Men's health has been getting more and more focus in the media during the 1990s. Sabo and Gordon (1995) conclude that health and macho attitudes are not allies and that men are the weaker sex (concerning health) ${ }^{8}$. Courtenay (2000) proposes that male power, the construction of masculinity, and unhealthy behaviours are intertwined:

By successfully using unhealthy beliefs and behaviours to demonstrate idealised forms of masculinity, men are able to assume positions of power - relative to women and less powerful men - in a patriarchal society that rewards this accomplishment. (p. 1397)

The reality of men often acting in manners that hamper their health in order to gain advantage and power, has serious impairing overtones for both gender equality, as well as for health betterment as a whole (cf. Sabo 2004:330-331).

\section{South African MHM - Analysing 123 issues ${ }^{9}$ cover pages}

MHM is the largest male magazine brand in the world ${ }^{10}$. From 2000 to 2005 it was consecutively selected as South Africa's best men's magazine. This particular magazine was selected for investigation because it has a very wide readership globally and in South Africa ${ }^{11}$, and because it overtly disseminates the core aim of empowering men with instruction on health affairs. As a result of the fact that I am also keen on promoting men's emotional and spiritual health, this specific magazine's focal point appropriately suffices as essential research data to gain insight into the cultural discourses regarding men's health. A data set of 123 issues of MHM was used, including most of the months between April 2001 and December 2011. The study is split into two main

8.There is an expanding controversy around the condition of men's health and how to deal with it. Global reports are increasing with regards to declining fertility, rising obesity, prostrate and testicular cancer, Viagra, increasingly stressful lifestyles as well as on men's ignorance of their bodies and a striking hesitation towards visiting the doctor (cf. Anthony 2003; Cowley 2003; Watson 2000; Woods 2002).

9.The reason for using this amount of $123 \mathrm{MHM}$ issues was because the publisher only had 123 out of the possible 129 months (within the range from April 2001 to had 123 2011) avilo publisher). This data set allowed for an analysis of 123 photographic images and 261 main cover stories and/or features. All cover pages revealed a homogeneous image main cover stories and/or features. All cover pages revealed a homogeneous image and representation of masculinity. Therefore, even if additional issues were analysis. The core goal was to generate an interpretation of the meaning of one cultural location, rather than to provide universal statements. Nevertheless, an investigation of other or more men's magazines, covering both an extended period and a contrasting demographical readership, may produce other results (e.g. in Germany or Australia where MHM is also distributed).

10.MMH was initiated in America in 1986, and globally (in Latin America first) in 1994. In the USA in 2006 it had 1.2 million subscribers and by 2007, 3.5 million MHM issues were internationally circulated monthly in 36 different countries (cf. $\mathrm{K}$. Barna, pers. comm., 26 June 2006; N. Jennings, pers. comm., 09 May 2006).

11.In South Africa, the magazine was started in May 1997. By August 2006 it already had 24000 countrywide subscribers. According to AMPS (All Media and Products Survey) (n.d.), the amount of people who read the magazine in South Africa, successfully gained ground from 719000 (between January to December 2004) to 1003000 readers (between January and December 2011). areas of analysis: (1) front cover images and (2) the thematic content of cover stories and/or discourses ${ }^{12}$.

\section{Cover page images}

A magazine's cover page characterises how it prefers to display its perspective on the world and differentiate itself from its rivals. Front covers revolve around the display and development of genre identity and are unmistakably the main selling feature. According to McCracken (1993:19), 'the cover serves to label not only the magazine, but the consumer who possess it'. Cover pages of men's magazines can indeed be seen as significant codes of visual dogma and necessitate critical interpretation. Alexander (2003:541) expounds that it can be viewed as 'windows of the future self'. He asserts that cover pages serve as selective scaffolding that influence both our ideas about ideal masculinity and of what follows in the magazine. I discovered that MHM cover pages disclose some particular patterns and themes. The main feature is the photographic illustration, which mirrors a uniform 'future self' to a particularly distinct crowd of men.

\section{Who is featured on the covers?}

Approximately 89\% (110 out of 123) of the covers in the data set highlighted white men considered to be between 23 and 36 years of age. The remaining 13 men were African or (socalled) Coloured men, in the same age group.

\section{The type of masculinity presented in the embodied images}

- $100 \%$ (123 out of 123 ) of the cover page images display the image of masculinity as a strong-muscled and vigorous body.

- On $92 \%$ (113 out of 123) of the issues a very handsome model man was depicted from around the waist upwards.

- $72 \%$ (88 out of 123 ) of the covers signify a sense of masculinity which Alexander (2003:542) typifies as 'wholesome masculinity'13. Here the fixed stare of the model is neither aggressive nor indifferent. Instead, he smiles at the viewer, either openly or self-consciously. Out of the outstanding 28\%, 21\% (26 out of 123) can be classified as Face-off masculinity, and 7\% (9 out of 123) as The Lean (using Bordo's terms, 1999) ${ }^{14}$.

- $59 \%$ (73 out of 123) of the cover page model men are without shirts (all of them are very muscular - pectorals, arms and 'six-pack' abdomen muscles are prominently

12.Front cover images and the content/discourses of cover stories were selected because it is obvious that it gives the most vivid expression of the magazines' main themes and intended messages. For a more detailed analysis of 60 front covers out of these issues, see Van der Watt (2007:437-455)

13.Alexander (2003:542) highlights that 'Wholesome masculinity stands in sharp contrast to the masculinity often presented on film, whether brute magnetism (Marlon Brando in A Streetcar Named Desire) or the stoic, hyperphysical (Arnold Schwarzenegger in Terminator 2 Judgement Day). It welcomes viewers to join in the pursuit of health and fitness by perusing the pages of the magazine'.

14.Face-off masculinity happens when male models gaze callously at viewers, opposing the viewer to see them in any other way than how they introduce themselves as mighty, invulnerable and emotionally bulletproof. The lean depicts a body that is sprawling and reclining or propped up against something. This is an body that is sprawling and reclining or propped up against something. This is an
attitude that is more commonplace in women's representation - not uninvolved; attitude that is more commonplace in women's representation -
but intentionally luring viewers to remain looking at their bodies. 
developed); the other (50) models were wearing mostly disclosing shirts that highlight their well-toned, muscular upper torsos.

\section{Content of presented discourses via cover stories/features: a thematic analysis ${ }^{15}$}

MHM cover pages reveal bodies to be adored but, notably, achieved with the least effort or displeasure. A close study of these covers' primary written content exposed these particular themes:

- $98 \%$ (120 out of 123 ) of the MHM issues uses the word sex or consist of sexual material (usually indicating virility or efficacy). The other three issues omit this, reason being that they are special editions (e.g. January 2004 'Anniversary 75th edition').

- $82 \%$ (101 out of 123) uses themes or formulations linked to a 'hard body', in other words: best body, muscle, firm abs and power.

- $48 \%$ (59 out of 123) refer to themes or formulations linked to 'fat reduction or weight loss', for example: lose your gut, less fat, in shape and get fit.

In summary, the most significant theme about masculinity, which is displayed on roughly all 123 cover pages, is that men should be (hetero-) sexually ${ }^{16}$ robust and urged to achieve, with regards to exhibiting sexual potency. A solid body with muscular power ${ }^{17}$ needs to be shaped and kept intact, in order to attain a dynamic sex life. Secondly, masculinity is specifically forged as being able to design a particular look: a hard-muscled (and stylish) sexy body. The third and little less flashy group of motifs - that is of fat or weight loss as well as fitness - supports this last-mentioned auxiliary aim.

In the developing 'new' South Africa, a context in dire need of affirmation in terms of its social well-being, MHM took advantage of (and continues to profit on) the bodily masculine

15.The approach/tool of thematic analysis was elected as qualitative analysis research method in order to identify, investigate and reports patterns (i.e. themes) within the chosen data set (of 123 MHM issues' cover pages). According to Braun and Clarke (2006:82) a 'theme captures something important about the data in relation to the research question, and represents some level of patterned response or meaning within the data set'. Thematic analysis as analytical tool thus helped to ssentially oranise and describe the article's data set, and furthermore interpret essentially organise and describe the article's data set, and furthermore interpret various aspects and oxplicit meanings be deemed as extending along with thematic Discourse Analysis in a small way (cf. Braun \& Clarke 2006:84-86)

16.I discovered no themes in the data set that back up or advocate homosexual execution of sexuality at all. Instead, it appears that homosexuality is forbidden in terms of the core message of what it means to be a 'real man'. This supposition is asserted by Whitton (2001:101) who contends that the 'sub-discourses underlying (MHM) sexuality illustrate particularly well the tensions inherent to the magazine's hegemonic masculinity. The most immediately noticeable sub-discourse is the total exclusion ... of homosexuality (an exclusion common to most hegemonic masculinities)'.

17.According to Boni (2002:473), who did a thorough analysis of the Italian edition of MHM, 'The medicalization of male sexuality leads to a sort of detachment, which means a distancing from one's body: the body becomes a sexual machine, which has to be controlled and kept functioning, and the sexual organs are transformed into "tools" or instruments by which the performance is accomplished. The penis into "tools" or instruments by which the performance is accomplished. The penis
becomes a gun (May 2000), a Formula 1 automobile which has to be constantly checked over (July 2000)' ideal, as an icon of a generally healthy society. But questions which spontaneously come to mind are: if these discourses are suggested as the ideal male image, what would men with severe physical disabilities, or men living in poverty, or men with erectile dysfunction, or a homosexual man feel or reflect about, upon reading the MHM? It can therefore be assumed, in light of the thematic analysis and arguments thus far, that the failure to fulfil a particular masculine ideal on a personal level may result in a crisis of identity and a disintegration of health.

\section{The harmful roots of hegemonic masculinity ${ }^{18}$ in MHM's focus}

Arran Stibbe (2004) scrutinised six issues of (the USA version of) MHM (from June to December 2000), to reveal that the primary discourses of $\mathrm{MHM}$ are founded on particular dogmatic premises. Stibbe's analysis (2004) indicates that:

Men's Health magazine, while giving abundant health advice, does so in a way that reproduces a type of hegemonic masculinity associated not with health, but with a variety of negative health behaviours. (p. 31)

The core issue at stake is, according to Stibbe, that MHM is drenched in stereotypical masculine beliefs and does not succeed in confronting the rhetoric of hegemonic masculinity, to the benefit of health. These assertions confirm the findings of the thematic analysis explicated in this article. It indeed amplifies the paradoxical fact that the typical way of life for men, as well as the core features of conventional, hegemonic, masculinity appear to be detrimental to male health. It has been confirmed by research that a large part of men's high death rates is connected to their gender roles and socialising habits. In effect, although many men are currently considering their bodily and psychological health, the proof for soaring ratios of stress-related illnesses and deaths, remain. (cf. Courtenay 2000; Helgeson 1995).

The exhaustive examination done by Stibbe (2004), is conducted within a critical discourse analysis framework ${ }^{19}$. He points out many dimensions of the ideal man created by MHM. These ideals seem to stretch outside the limits of plain health concerns. Stibbe (2004:34-36) describes the ideal man as a bodybuilder; a meat eater; a beer drinker; a convenience

18.The concept of hegemonic masculinity - which epitomises a presently endorsed way for justifying patriarchy - has been popularised by Connell (1995; 2005). Although it has been critiqued in a variety of ways, it continues to be implemented to keep attention focused on the well-known feminist acumen that, typically, gender power relationships are unjust to women. Hegemonic masculinity is usually utilised (as a sort of cultural exemplary) to describe types of masculinities that maintain the superior social rank, both in relation to women as well as to other men or masculinities (Toerien \& Durrheim 2001.51). But, it is significant to note that hegemonic masculinity is not immovable or permanent. Because, as soon as the prerequisites for the justification of patriarchy shift, the foundations for the supremacy of a specific masculinity are destroyed. Consequently, new types of hegemony or fresh plans to preserve the previous type, need to be created (Connell 1995:77). Notwithstanding, in whichever form, hegemonic masculinity persists as a quintessential goal which is unattainable for many men, although it epitomises a yardstick against which most men measure their male identities.

19. Many researchers have attempted to make sense of the various discourses in MHM recently. Whitton (2001:100-104) demonstrates that the primary convictions in MHM advocates a hegemonic masculinity that tries to harmonise visible features of the 'traditional' man with aspects of the 'new age' man. But, eventually the final 'product' is often puzzling, and even paradoxical. Toerien and Durrheim (2001:50) product' is often puzzling, and even paradoxical. Toerien and Durrheim (2001:50) have also made a discourse analysis of 15 editions of South African MHM. Two They deal with an issue that is essentially unsettling for many men today: how to They deal with an issue that is essentially unsettling for many men today: how to
find the core of their masculinity while dissociating themselves from critique of stereotypical masculinity. 
food eater; a sexual champion; and a television watcher. For the aim of this article, I concisely focus on the two aspects of 'bodybuilder' and 'sexual champion', in order to indicate further how MHM is drenched in stereotypical masculine beliefs and does not succeed in confronting the rhetoric of hegemonic masculinity, to the benefit of health.

\section{The ideal $\operatorname{man}^{20}$ as a bodybuilder}

In what way can the so-called ideal man use his body to verify that he advocates hegemonic masculinity? Researchers (cf. Mishkind et al. 1986) discovered that most boys and young men strive to mirror the muscular man image; i.e. a well-grown and broad chest, powerful arm muscles and shoulders, as well as a narrowing down to a slim midriff. MHM primarily praises the male body as a commodity to be idolised and relished. It supplies an explicit acumen into the way in which the ideal bodily depiction of manliness is displayed in the second millennium, while designating power, energy, health, and a fit physique implicit of material prosperity.

According to Stibbe (2004:36-37) the main aim of MHM, set up via compulsory objectives, is reproducing male power through boosting muscle size. Cover page models - a crowd of men shaped alike - mirror the ideal body figure: sleek, bronzed, enormously muscular, etc. Thus, the creation of the ideal man as immensely muscular ${ }^{21}$, aids the utopian ambition of duplicating male power ${ }^{22}$. However, Stibbe also pinpoints the fact that ideals of huge muscles can cause unhealthy body images, eating disorders, steroid habits as well as the present 'muscle dysmorphia' disorder in bodybuilders ${ }^{23}$. This echoes research findings (e.g. Barlett, Vowels \& Saucier 2008; Botta 2003; Morry \& Staska 2001;

20.A gender ideal is socially constructed within a particular cultural and historical setting. It is determined by various intermediary aspects which causes it to change from time to time, for instance religion, ethnicity, nationality, race, age and class. Alexander (2003:537) asserts that gender ideals are shaped by the shared discourses or models of gender that the biggest part of society welcomes as
dister suitable femininity or masculinity. Therefore, gender displays describe the myriad ways in which we disclose, through our words and body language, that we identify or comply with notions of being masculine or feminine. George Mosse, according to Viljoen (2008:314), views the Western masculine ideal as the blend of middleclass, Christian norms - honesty, strength, courage and self-control - and an idea of the male physique drawn from classical Greek philosophy and art.

21.Cf. McCreary, Saucier and Courtenay (2005) who explicated that men striving to become physically stronger sensed discord concerning societal expectations that wants them to achieve, and be strong and ambitious. These men also stated that balancing relaxational and occupational roles are not easy.

22.Messner (1988) contends that muscularity in men can be viewed as an indication of dominance over women, as well as over differing men who display contrasting masculinities. This is partly on account of the fact that physical power is connected to force, technical ability and brutality, i.e. with hegemonic masculinity. See also Dube (2015), who explicates the notion of 'muscular Christianity' in contemporary South Africa.

23.Research (cf. Bordo 1999:218-219) shows that the prevalence of muscle dysmorphic disorders among men, is rising. It often takes onset during the latter part of the teenage stage, the average is 19.4 years (Pope et al. 2000:6). It implies that boys' and men's beliefs about their conduct and self-images are adversely influenced by some ideals of masculinity. Muscle dysmorphia is typed as a particular kind of BDD (body dysmorphic disorder), which can also be called reverse anorexia nervosa or bigorexia. Boys and men suffering from muscle dysmorphia are obsessed with the issue of not having big enough muscles. They incessantly inspect themselves in front of mirrors; can be upset because of missin their gym session, or use possibly perilous drugs (e.g anabolic steroids). This can their gym session, or use possibly perilous drugs (e.g. anabolic steroids). This can cause them to be family, or fail at completing their work, because of physical workouts (at the gym). The concept of 'the Adonis Complex' was created by Pope et al. (2000:6). It depicts an array of usually secret, but surprisingly common, These concerns can be diverse, ranging from hair loss, the use of anabolic steroids, excluding fatty diets, binge eating and penis size, to an obsession with becoming more muscular.
Spitzer, Henderson \& Zivian 1999) that specifically explicate that there is a direct parallel between repeated use of steroids, elevated degrees of body image discontent, and the amount of time spent reading fitness and health magazines.

According to Frederick, Fessler and Haselton (2005:82), various studies on the topic of body image satisfaction indicate that most men, when given a choice, will opt for a more idealised version of their present body, i.e. one with more powerful muscles. Thus, the media's influence - and here specifically magazines - on men's body ideals and its powerful ability to bring about bodily discontent, seems irrefutable.

The ultimate question however begs to be asked: is this 'big, hard and up! !' $^{2 \prime}$ creed a really healthy one to live by?

\section{The ideal man as a sexual champion}

It is very clear that supreme heterosexual sexual intercourse is one of MHM's aims. But, contends Stibbe (2004:47), the target is not merely sex of an excellent kind, but 'tons of sex'. Consequently, an important discourse in MHM cover pages' displays of intimate relationships is a rendering of sex as simple, unavoidable, and without strings attached. Readers' receiving and giving of sexual fulfilment is apparently guaranteed. Many intimate, heterosexual relations are indeed currently characterised by 'plastic sexuality', as identified by Giddens (1992:2). In other words, sexuality becomes decentred ${ }^{25}$, liberated from the requirements of conception. See illustration number 1 of the February 2008 edition here below as an example, used with permission of Jones (pers. comm., 22 June 2008) (Figure 1).

Within this framework of thought about sexuality, reaching sexual gratification or emotional closeness is perceived of in technical means of fabrication, i.e. as if within commercial domains. Furthermore, the notion that readers must incessantly go all out to attain unattainable ideals of sexual elation, is amplified by the magazines' maxim, i.e. sex constitutes an integral component of the meaning of manhood.

Anna Rogers (2005), after analysing MHM and Loaded magazines through qualitative research, asserts that in these magazines:

A methodical approach is recommended ... This extends to issues such as performance anxiety, failed sexuality, or 'bad sex' in that they are addressed using terminology that suggests the reader might work on his sex life just as one might work with a car: 'Sex garage'. (p. 188)

24.Dittes (1985:140-141) proposes that 'To be a man is to be expected, and to expect oneself, to be forever "up," even "one-up," however capricious a man's private parts in responding to appeals to performance-on-demand: "Batter up: You're up kid!" "Get your speed up" "Wake up!" "Chin up!" "Grow up." "Measure up"”. This striking concept of so-called 'up-manship' has influenced the choice of title for this article.

25.Bauman (1991:202) states therefore that relationships 'tend to be confused, ambiguous, tension-ridden ... likely to generate profound anxiety'; whilst Plummer (1996:xiv-xv) confirms this notion by highlighting the increasing uncertainty of a so-called 'supermarket of sexual possibilities'. 


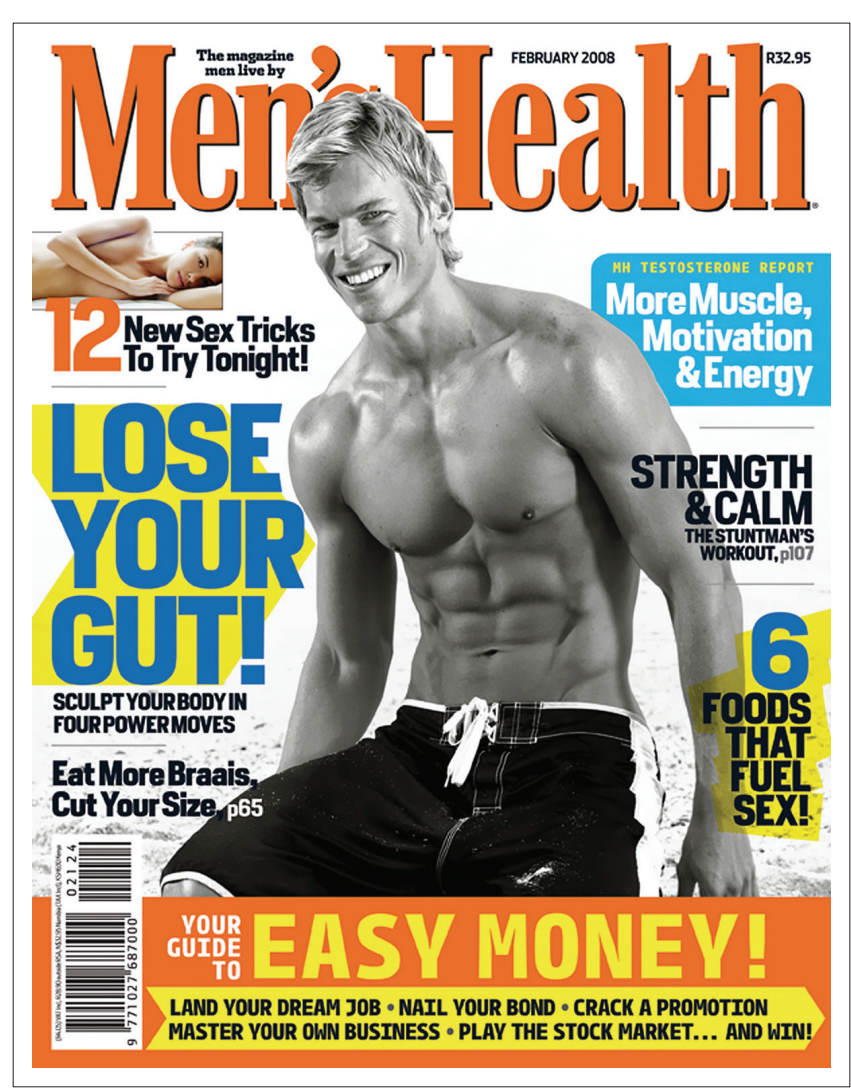

FIGURE 1: Illustration 1.

The idea of a sexual mode of production ... seems to have very little to say about closeness and commitment in sexually intimate relationships. (p. 191)

It has been pointed out by research (cf. Courtenay 2000: 1391-1392) that men are more inclined to be sexually active while intoxicated, and to have more sexual companions than women. Therefore, men are also twice as likely as women to contract STDs Indeed, in this article's analysis of discourses on MHM cover pages regarding advice on the ultimate ways to enjoy sex, as well as in all the narratives and depictions of euphoric sex, contraception (e.g. condoms) are not at all referred to. This generates an unproblematic and affirmative image of uncommitted ${ }^{26}$ and risky sex. Moreover, there is no mention of building intimate relationships as strong and well-rooted connections, distinguished by long-term commitment and mutual trustworthiness - values that are generally accepted as normative within Christian notions of sexual relations. Instead, it can be inferred from the thematic analysis of its cover page images and discourses, that MHM favours an eternal and thriving bachelorhood and can thus foster a culture of unaccountability and irresponsibility.

With regards to intimate relationships, the MHM's celebration of autonomy and fear of dependence seem to project a view of committed relationships, and by implication marriage, as a form of social constraint, preventing young men from living a life of consumptive and sexual freedom. Marriage seems to

26.Viljoen (2008:239) asserts that MHM as well as FHM and GQ 'all employ the silent but emphatic omission of almost all references to wives and children, preferring instead to depict their subjects and readers as eternally uncommitted'. represents a restriction on masculine forms of self-definition. From a responsible Christian pastoral care perspective $\mathrm{e}^{27}$ this is problematic and can lead to unhealthy and disintegrated masculinity forms.

\section{Conclusion}

In this article, by theologically exploring magazines, I attempted to concretise practical and pastoral theology as valid interpretation frameworks of culture. Therefore, in this article contemporary cultural discourses concerning masculinities were investigated, in order to assist practical theologians and pastoral caregivers to reflect critically on current images and themes in the media that co-regulate male identities.

Via this investigation I assert that theory formation within practical theology can be augmented and pastoral care interventions fostered that resist harmful and corrosive masculinity types. Pastoral caregivers are invited to help create and endorse men and masculinities that embody integrated health, through respectful intimacy and human dignity.

The MHM's thematic analysis exposed the latent uncertainties and problems which the wider mass media, as well as men's lifestyle magazines in particular, produce for understanding masculinity nowadays. The main discourses, as well as MHM's objective of making maleness profitable, bring about less healthy consequences. This causes a moral impasse, because when unreachable and mythical ideals of maleness are utilised to fuel the consumer mindset, masculinities can become detrimental and ruinous, instead of bringing about life-giving vitality and dignity. Furthermore, this heralds the possibility of a masculine self-realising its deepest meaning not through sacrifice and ethical responsibility (as within a Christian worldview), but through the tragedies and triumphs of love and sex, and the idealisation of having a perfect, hard macho body.

In light of these above-mentioned trends I therefore contend that - from a pastoral care perspective, many men (including many Christian men) need an alternative interpretation framework other than the reigning cultural trends to live by. We need a fresh pastoral hermeneutic in order to discover deeper meaning and authentic relational intimacy, within a digitally networked society. I am aware that the mass media sometimes contribute valuable aspects toward the establishment of healthy masculinities. However, for many men - maybe especially for Christian men - the mass media's in-your-face illustrations and its themes and/or motifs, will not suffice.

Fundamentally, most men require an integrated view of health. One that is able to produce a substantial manhood

27.As researcher $\mathrm{I}$ am aware of the fact that $\mathrm{I}$ cannot discharge myself of my epistemological (i.e. practical theological) engagements. Thus, I know that I did not interpret the analysed data in an epistemological void. I attempted to (very basically) infer the significance of the patterns/themes and their broader meanings and implications theologically. It has been made clear that the theoretical framework within which this thematic analysis is done, is a pastoral care perspective (i.e. hermeneutic). From this perspective, I place significant value on marriage as a God given space for relationships that are (amongst other things), distinguished by long-term commitment (fidelity) as well as mutual trustworthiness and sacrifice. 
within shifting expectations of diverse, global societies and cultural discourses. This article explicated the core issue at hand: men are basically required to rearrange themselves relative to the dominant power relations that surround them, as well as to their own embodiment. This repositioning can align them to become able to create and re-invent fresh ways of being healthy men.

It was suggested that men need to combat the adverse dimensions of stereotypical masculinity that threaten their health, and simultaneously cling to the constructive features of manhood and male lifestyles that boost men's bodily vigour. In other words, a realistic and proactive health scenario requires of men to critically assess the so-called 'big, hard and up' creed. I indicated how this creed incites a utilitarian view of sexuality within a culture of performancedriven masculinity, which subsequently fuels anxieties that can lead to unhealthy issues, such as body image dissatisfaction. It was made clear that it is indeed possible that poor male health is exacerbated by many men's excessive attempt to try and live up to the macho image propagated in MHM. And furthermore, that popular commercialised male lifestyles - promoted by main images and themes found in MHM - can actually be dangerous to men's holistic health.

Pastoral care practitioners and caregivers are therefore encouraged to help men to meaningfully challenge the reigning 'big, hard and up!' creed, and to instead facilitate integrated and life-giving theological perspectives on masculinities, that can generate lasting vitality and a vulnerable (spiritual-emotional) courage to embody manhood.

\section{Acknowledgements Competing interests}

The author declares that he has no financial or personal relationships which may have inappropriately influenced him in writing this article.

\section{References}

Alexander, S.M., 2003, 'Stylish hard bodies: Branded masculinity in Men's Health Magazine', Sociological Perspectives 46(4), 535-554.

AMPS, n.d., South African audience research foundation: Magazines \& newspaper readership, viewed 01 August 2012, from http://www.saarf.co.za/amps/ readership.asp

Anthony, L., 2003, 'The weaker sex', Sunday Times, 06 April, p. 23.

Barlett, C.P., Vowels, C.L. \& Saucier, D.A., 2008, 'Meta-analyses of the effects of media images on men's body-image concerns', Journal of Social and Clinical Psychology $27,279-310$.

Bauman, Z., 1991, Modernity and ambivalence, Polity, Cambridge.

Beynon, J., 2002, Masculinites and culture, Open University press, Buckingham.

Boni, F. 2002, 'Framing media masculinities: Men's lifestyle magazines and the biopolitics of the male body', European Journal of Communication 17 $465-478$.

Bordo, S., 1999, The male body: A new look at men in public and in private, Faggar, Strauss \& Giroux, New York.

Botta, R.A., 2003, 'For your health? The relationship between magazine reading and adolescents' body image and eating disturbances', Sex Roles 48, 389-399.

Braun, V. \& Clarke, V. 2006, 'Using thematic analysis in Psychology', Qualitative Research in Psychology 3, 77-101.

Budgeon, S., 2003, 'Identity as an embodied event', Body and Society 9, 35-55.

Castells, M., 1999, 'An introduction to the information age', in H. MacKay \& T. O'Sullivan (eds.), The media reader: Continuity and transformation, pp. 398-410, Sage Publications, London.
Chamberlain, K. \& Hodgetts, D., 2008, 'Social psychology and media: Critical considerations, social and personality psychology', Compass 2(3), 1109-1125.

Connell, R.W., 1995, Masculinities, Cambridge Press, London.

Connell, R.W., 2005, Masculinities, 2nd edn., University of California, Los Angeles.

Courtenay, W., 2000, 'Constructions of masculinity and their influence on men's well-being: A theory of gender and health', Social Science and Medicine 50(1), 1385-1401.

Cowley, G., 2003, 'The biggest prize of all', Newsweek, 16 June, p. 27.

Davis, K., 2002, 'A dubious equality: Men, women and cosmetic surgery', Body \& Society 8, 49-65.

Dittes, J.E., 1985, The male predicament: On being a man today, Harper \& Row, San Francisco.

Dube, S., 2015, 'Muscular Christianity in contemporary South Africa: The case of the mighty men conference', HTS Teologiese Studies/ Theological Studies 71(3), Art \#2945, 9 pages. http://dx.doi.org/10.4102/hts.v71i3.2945

Durham, M.G. \& Kellner, D.M., (eds.), 2001, Media and cultural studies: Keyworks, Blackwell Publishing, Oxford.

Frederick, D.A., Fessler, D.M.T. \& Haselton, M.G., 2005, 'Do representations of male muscularity differ in men's and women's magazines?', Body Image 2, 81-86.

Giddens, A., 1992, The transformation of intimacy, Polity, Cambridge.

Helgeson, V., 1995, 'Masculinity, men's roles and coronary heart disease', in D. Sabo \& F. Gordon (eds.), Men 's health and illness: Gender, power and the body, pp. 68104, Sage Publications, London.

Lemon, J., 1991, 'Images of men and the crisis of masculinity: An exploratory study', MA thesis, University of South Africa.

Louw, D.J., 2008, Curae Vitae: Illness and the healing of life in pastoral care and counselling: A guide for caregivers, Lux Verbi, Wellington.

Luciano, L., 2001, Looking good: Male body image in modern America, Hill and Wang, New York.

McCracken, E., 1993, Decoding women's magazines, Macmillan, London.

McCreary, D.R., Saucier, D.M. \& Courtenay, W.H., 2005, 'The drive for muscularity and masculinity: Testing the associations among gender-role traits, behaviors, attitudes, and conflict', Psychology of Men \& Masculinity 6(2), 83-94.

Messner, M.A., 1988, 'sport and male domination: The female athlete as contested ideological terrain', Sociology of Sport Journal 5, 197-211.

Mishkind, M.E., Rodin, J., Silberstein, L.R. \& Striegel-Moore, R. H., 1986, 'The embodiment of masculinity: Cultural, psychological, and behavioral dimensions', American Behavioural Scientist 29, 545-562.

Morry, M.M. \& Staska, S.L., 2001, 'Magazine exposure: Internalization, selfobjectification, eating attitudes, and body satisfaction in male and female university students', Canadian Journal of Behavioural Science 33, 269-279.

Pettigrew, J. 2007, Brutes in suites: Male sensibility in America, 1890-1920, Johns Hopkins University Press, Baltimore.

Plummer, K. 1996, 'Foreword', in W. Simon (eds.), Postmodern sexualities, pp. ix-xvi, Routledge, London.

Pope, H., Phillips, K. \& Olivardia, R., 2000, The Adonis complex: How to identify, treat and prevent body obsession in men and boys, Simon \& Schuster, New York.

Ricciardelli, R., Clow, K.A. \& White, P., 2010, 'Investigating hegemonic masculinity: Portrayals of Masculinity in Men's Lifestyle Magazines', Sex Roles 63, 64-78.

Rogers, A., 2005, 'Chaos to control: Men's magazines and the mastering of intimacy', Men and Masculinities 8(2), 175-194.

Sabo, D., 2004, 'Masculinities and men's health: Moving toward post-superman era prevention', in M.S. Kimmel \& M.A. Messner (eds.), Men's lives, 6th edn., pp. 321-344, Pearson Education Inc., Boston.

Sabo, D. \& Gordon, D.F. (eds.), 1995, Men's health and illness: Gender, power and the body, Sage, Thousand Oaks.

Salzman, M., 2012, The big little book of nexts: Trendspotting for 2012, viewed 13 October 2012, from http://us.havaspr.com/wp-content/uploads/2011/11/ Trends2012_PR_FIN.pdf

Sharkey, A., 2000, 'New media, new men: The lost paradigm of male normality', in G. Malossi (ed.), Material man: Masculinity, sexuality, style, pp. 170-179. Harry N. Abrams Inc., New York.

Spitzer, B.L., Henderson, K.A. \& Zivian, M.T., 1999, 'Gender differences in population versus media body sizes: A comparison over four decades', Sex Roles 40, 545-565.

Stibbe, A., 2004, 'Health and the social construction of masculinity in men's health magazine', Men and Masculinities 7, 31-51.

Tasker, Y., 1993, 'Dumb movies for dumb people: Masculinity, the body, and the voice in contemporary action cinema', in S. Cohan \& I.R. Hark (eds.), Screening the male: Exploring masculinities in Hollywood cinema, pp. 230-244. Routledge, New York.

Toerien, M., \& Durrheim, K., 2001, 'Power through knowledge: Ignorance and the "Real Man", Feminism \& Psychology 11(1), 35-54.

Van der Watt, J.S., 2007, 'Images of men and masculinities in cultural contexts: A pastoral assessment', DTh thesis, Department of Practical Theology and Missiology, Stellenbosch University.

Van der Watt, J.S., 2012, 'The peril of patriarchal power: Distorting dignity and intimacy in (male) sexuality', in D.J. Louw, D.T. Ito \& U. Elsdörfer (eds.), Encounter
in pastoral care and spiritual healing: Towards and integrative and intercultural in pastoral care and spiritual healing: Towad
approach, pp. 90-111, LIT Verlag, Berlin. 
Van der Watt, J.S. \& Louw, D.J., 2012, 'Masculine identity and the projection of "male images" in mass media: Towards a pastoral hermeneutics in theory formation', Nederduitse Gereformeerde Teologiese Tydskrif 53(3\&4), 353-368.

Viljoen, S., 2005, 'The aspirational aesthetics of "gentlemen's pornography"', in K. van Marle (eds.), Sex, gender becoming: Post-apartheid reflections, pp. 41-60, Pretoria University Law Press, Pretoria.

Viljoen, S., 2008, 'Masculine ideals in post-apartheid South Africa: The rise of men's glossies', in A. Hadland, E. Louw, S. Sesanti \& H. Wasserman (eds.), Power, politics and identity in South African media, pp. 312-342. Human Sciences Research Council, Cape Town.
Watson, J., 2000, Health, culture and identity, Open University Press, Philadelphia. Whitton, G., 2001, 'Masculinities and men's Health', Agenda 47, 99-104.

WHO, n.d., 'What is the WHO definition of health?', viewed 03 March 2015, from http://www.who.int/suggestions/faq/en/

Woods, M., 2002, Killing them subtly - Social determinants in men's health, viewed 13 February 2014, from http://www.menshealth.uws.edu.au/documents

Woodward, J. \& Pattison, S., 2000, 'An introduction to pastoral and practical theology', in J. Woodward \& S. Pattison (eds.), The Blackwell reader in pastoral and practical theology, pp. 1-19, Blackwell Publishers, Oxford. 